\title{
Jailed Iranian physicist released on bail
}

Omid Kokabee has been granted temporary medical leave after having a kidney removed.

\section{Michele Catanzaro}

25 May 2016

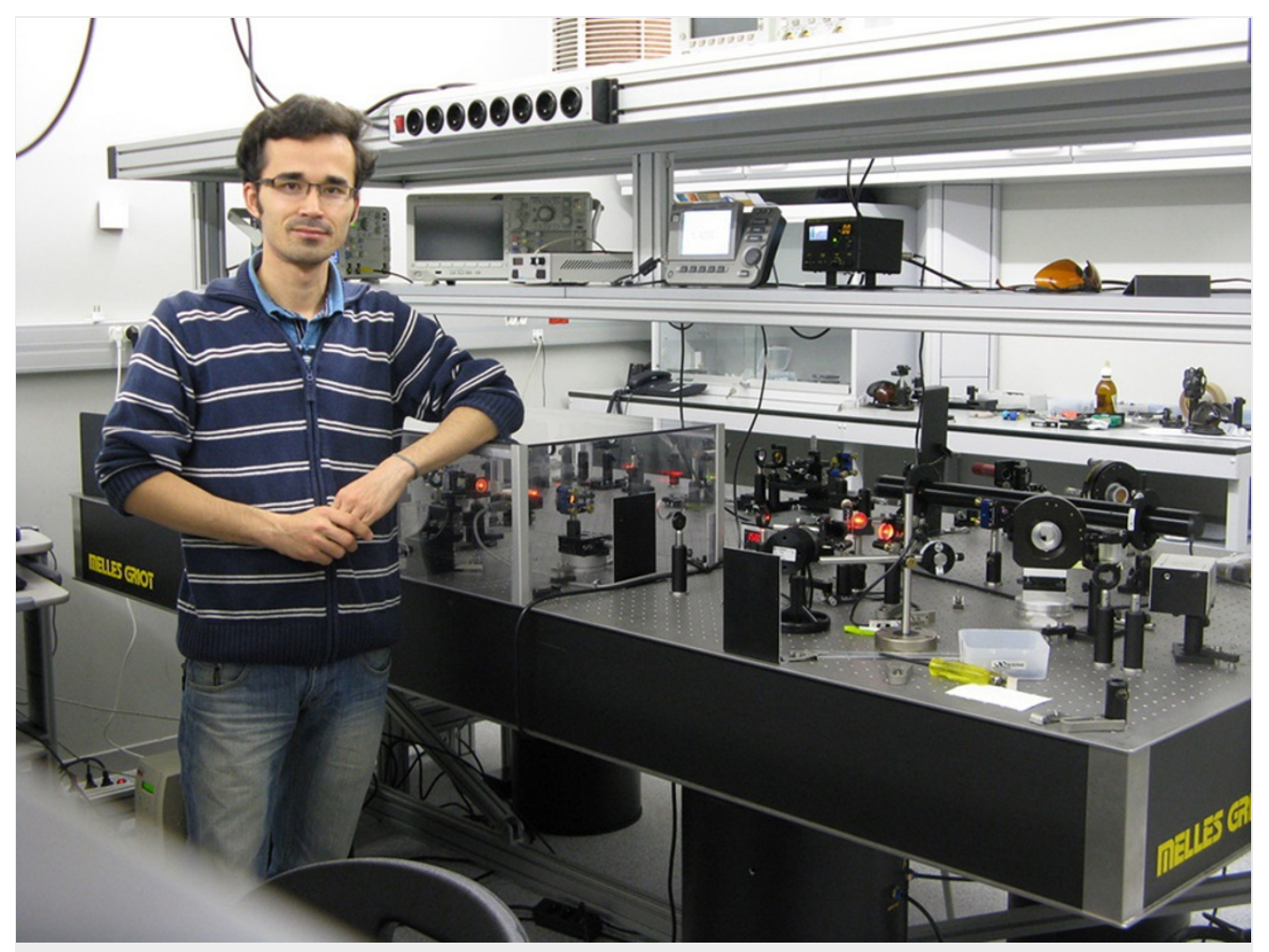

Omid Kokabee, before his imprisonment.

Omid Kokabee, a former physics PhD student who has been in prison for more than five years in Iran, has been granted a brief medical leave on bail to recover from kidney-cancer surgery, sources close to the situation tell Nature.

The 33-year-old left a hospital in Tehran on 25 May — where he has been recovering from the surgery since 20 April — and is expected to be allowed to stay out of prison for one to three months after his friends posted a bail of 5 billion Iranian rials (US\$165,000).

Officially, the medical leave must be renewed every two weeks, but Kokabee's contacts hope to have the leave extended further, by appealing to an article of Iran's penal code that permits the postponement of a jail sentence that may harm a prisoner's health.

The doctoral student, who has studied laser physics in Spain and the United States, was arrested in Iran in 2011 while visiting family, and was sentenced to ten years in prison for "collaboration with a hostile government" and "illegal enrichment". The young scientist and his supporters say that he was sentenced for refusing to cooperate with Iran's nuclear programme.

Numerous appeals have been made for Kokabee's release by human rights organizations and scientific societies — including a letter signed by 31 Nobel physics laureates. In 2014, Iran's supreme court granted Kokabee a retrial, but another court upheld the sentence in 2015 .

\section{Declining health}

Last year, both the American Physical Society and the American Association for the Advancement of Science requested Kokabee's release on humanitarian grounds, noting that the doctoral student had become increasingly ill during his incarceration. Both societies have given Kokabee human-rights awards. 
including kidney stones and stomach pain, as early as December 2012. But it was only in November 2015 that Kokabee was transferred to hospital for treatment, and — during a second visit to hospital — a sonogram revealed a cancer in his right kidney.

In April, the kidney was removed. Kokabee's contacts say that if he had received the sonogram years earlier, his health might not have declined to the point that the total removal of the kidney was needed. Other human-rights groups and North American academics have also suggested that a lack of proper medical treatment has exacerbated Kokabee's ill health.

Also concerning are the conditions that await Kokabee if he returns to prison, sources with knowledge of the situation say. Since September 2014, they told Nature, he has been held in a windowless, bedbug-plagued quarantine ward with other political prisoners and deprived of opportunities for sport or physical activity. Many of the prisoners are reported to have physical health problems or be suffering from depression.

Nature | doi:10.1038/nature.2016.19976 